\title{
GPS radio occultation with CHAMP and SAC-C: global monitoring of thermal tropopause parameters
}

\author{
T. Schmidt, S. Heise, J. Wickert, G. Beyerle, and C. Reigber \\ GeoForschungsZentrum Potsdam, Department 1: Geodesy and Remote Sensing, Potsdam, Germany \\ Received: 20 September 2004 - Published in Atmos. Chem. Phys. Discuss.: 1 December 2004 \\ Revised: 23 February 2005 - Accepted: 12 May 2005 - Published: 15 June 2005
}

\begin{abstract}
In this study the global lapse-rate tropopause (LRT) pressure, temperature, potential temperature, and sharpness are discussed based on Global Positioning System (GPS) radio occultations (RO) from the German CHAMP (CHAllenging Minisatellite Payload) and the U.S.Argentinian SAC-C (Satelite de Aplicaciones Cientificas-C) satellite missions. Results with respect to seasonal variations are compared with operational radiosonde data and ECMWF (European Centre for Medium-Range Weather Forecast) operational analyses. Results on the tropical quasi-biennial oscillation (QBO) are updated from an earlier study. CHAMP RO data are available continuously since May 2001 with on average 150 high resolution temperature profiles per day. SAC-C data are available for several periods in 2001 and 2002. In this study temperature data from CHAMP for the period May 2001-December 2004 and SAC-C data from August 2001-October 2001 and March 2002-November 2002 were used, respectively. The bias between GPS RO temperature profiles and radiosonde data was found to be less than $1.5 \mathrm{~K}$ between 300 and $10 \mathrm{hPa}$ with a standard deviation of $2-3 \mathrm{~K}$. Between $200-20 \mathrm{hPa}$ the bias is even less than $0.5 \mathrm{~K}$ ( $2 \mathrm{~K}$ standard deviation). The mean deviations based on 167699 comparisons between CHAMP/SAC-C and ECMWF LRT parameters are $(-2.1 \pm 37.1) \mathrm{hPa}$ for pressure and $(0.1 \pm 4.2) \mathrm{K}$ for temperature. Comparisons of LRT pressure and temperature between CHAMP and nearby radiosondes $(13230)$ resulted in $(5.8 \pm 19.8) \mathrm{hPa}$ and $(-0.1 \pm 3.3) \mathrm{K}$, respectively. The comparisons between CHAMP/SAC-C and ECMWF show on average the largest differences in the vicinity of the jet streams with up to $700 \mathrm{~m}$ in LRT altitude and $3 \mathrm{~K}$ in LRT temperature, respectively. The CHAMP mission generates the first long-term RO data set. Other satellite missions will follow (GRACE, COSMIC, MetOp, TerraSAR-X, EQUARS) generating together some thousand temperature profiles daily.
\end{abstract}

Correspondence to: T. Schmidt

(tschmidt@gfz-potsdam.de)

\section{Introduction}

In the climate change discussion tropopause parameters have received more attention in recent years since they describe climate variability and change, and are crucial for the understanding of stratosphere-troposphere exchange (Holton et al., 1995; Sausen and Santer, 2003; Santer et al., 2004; Schoeberl, 2004). Therefore the continuous identification and monitoring of the tropopause on a global scale is an important goal in atmospheric and climate research. Several tropopause climatologies have been published in recent years, especially for the tropical or polar tropopause using either radiosonde data or global weather re-analyses (Hoinka, 1998; Highwood and Hoskins, 1998; Hoinka, 1999; Randel et al., 2000; Highwood et al., 2000; Seidel et al., 2001; Zängl and Hoinka, 2001; Gettelman and de Forster, 2002).

The availability of GPS radio signals has introduced a new promising remote sensing technique for the Earth's atmosphere (Melbourne et al., 1994; Kursinski et al., 1997; Anthes et al., 2000). The GPS based RO exploits these signals received onboard a Low Earth Orbiting (LEO) satellite for atmospheric limb sounding. The GPS signals are influenced by the atmospheric refractivity field resulting in a time delay and bending of the signal. The atmospheric excess phase is the basic observable that is measured with millimetric accuracy (Wickert et al., 2001a). This is the basis for precise refractivity and temperature profiles (Melbourne et al., 1994; Kursinski et al., 1997; Kuo et al., 2004; Wickert et al., 2004a; Hajj et al., 2004).

The proof-of-concept GPS RO experiment GPS/MET (GPS/METeorology) performed between 1995 and 1997 has demonstrated for the first time the potential of GPS based limb sounding from LEO satellites for deriving atmospheric temperature and tropospheric water vapor profiles (Ware et al., 1996; Kursinski et al., 1997; Rocken et al., 1997). Further missions with radio occultation experiments followed (Ørsted, SAC-C, and CHAMP). CHAMP was launched in July 2000 with an initial altitude of about $450 \mathrm{~km}$, whereas

(C) 2005 Author(s). This work is licensed under a Creative Commons License. 


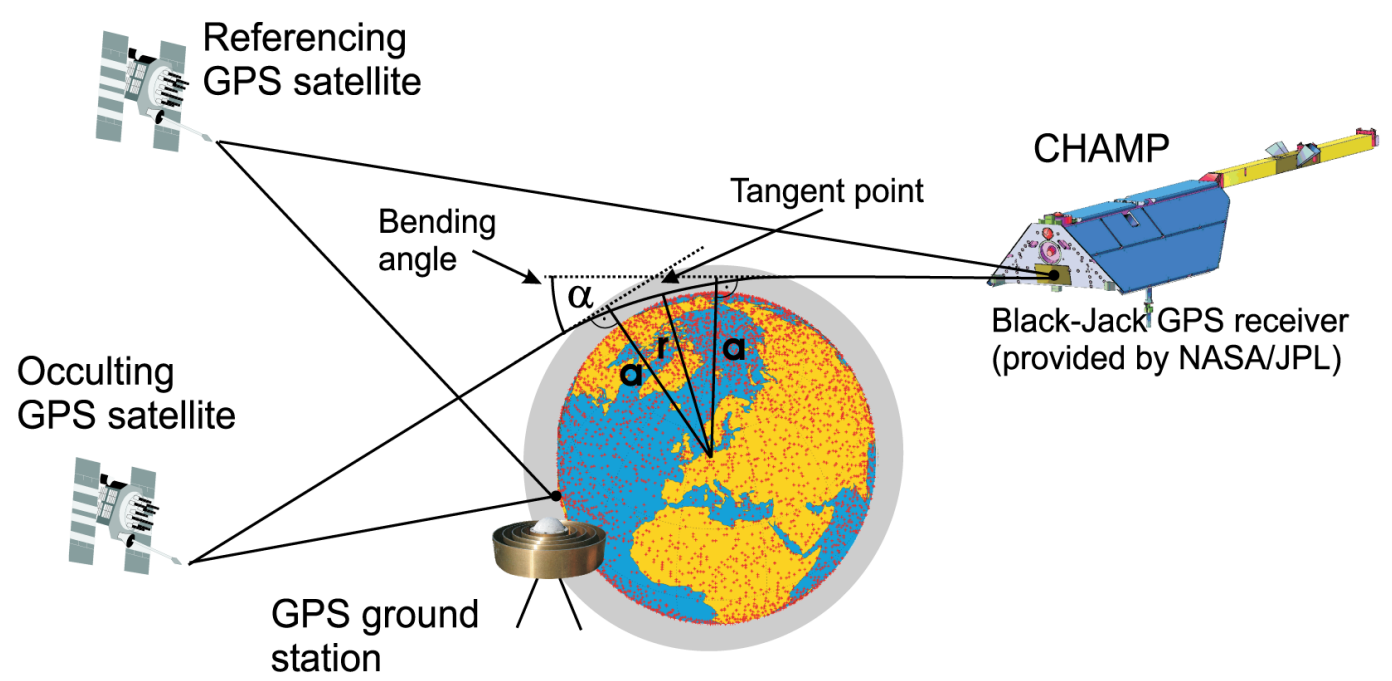

Fig. 1. GPS radio occultation principle (after Wickert et al. (2004a)).

SAC-C was launched in November 2000 (initial altitude of about $750 \mathrm{~km}$ ). Both satellites have an almost circular and near polar orbit, and are equipped with the same type of Black-Jack GPS receiver provided by NASA/JPL (Jet Propulsion Laboratory). The CHAMP RO experiment was successfully started on 11 February 2001 and provides RO data continuously in an operational manner since mid2001 (Wickert et al., 2001b, 2004a; Schmidt et al., 2005). Because of numerous software uploads and tests on SAC-C the amount of data from this satellite has varied over the last years (Hajj et al., 2004) so that SAC-C data for this study are only available from August 2001-October 2001 and March 2002-November 2002. First results from the GPS RO experiment aboard the US-German GRACE (Gravity Recovery And Climate Experiment) mission are available for 28 and 29 July 2004 (Wickert et al., 2005).

First investigations of the thermal structure and variability in the tropical upper troposphere and lower stratosphere (UTLS) region based on GPS RO measurements were performed by Nishida et al. (2000) and Randel et al. (2003) on the basis of the GPS/MET data from 1995-1997 focused on the so-called "prime-times" (June-July 1995, DecemberFebruary 1996/97) (Rocken et al., 1997). Applications of CHAMP RO data to that region with a 1- and 2.5-year data set were shown by Schmidt et al. (2004a,b).

In this paper we present a first overview of global lapserate tropopause (LRT) parameters (WMO, 1957) derived from about 3.5 years of GPS RO measurements and compare the results with radiosonde data and ECMWF operational analyses. We give a short overview of the measuring principle and data quality of the CHAMP/SAC-C temperature data in Sect. 2. Sect. 3 briefly describes the data used in this study and Sect. 4 introduces the algorithms for the determination of the tropopause parameters for the CHAMP/SAC-C and
ECMWF temperature profiles. In Sect. 5 we discuss the results for CHAMP/SAC-C and comparisons with radiosondes and ECMWF data, whereas Sect. 6 is an update of an earlier study (Schmidt et al., 2004b) to the equatorial QBO pattern found in the CHAMP temperature data. Finally, Sect. 7 gives a summary and conclusions.

\section{Measuring principle and data quality}

\subsection{Data processing}

A detailed description of deriving vertical atmospheric profiles from CHAMP/SAC-C occultation measurements is presented by Wickert et al. (2001b, 2004a), Hajj et al. (2004), or Kuo et al. (2004). The Black-Jack GPS receiver onboard CHAMP/SAC-C records phase and amplitude variations with high temporal resolution $(50 \mathrm{~Hz})$ during an occultation event (Fig. 1). By using high precision orbit information from CHAMP/SAC-C and the occulting GPS satellites (König et al., 2005) the atmospheric excess phase can be extracted which is related to a bending angle profile. A double differencing method is applied to remove clock errors (Wickert et al., 2001a). For this purpose a GPS ground station network is operated jointly by JPL and GeoForschungsZentrum (GFZ) Potsdam. Ionospheric effects are corrected by a linear combination of the bending angles derived from the two GPS frequencies and the known dispersion relation for microwave frequencies in the ionosphere (Vorobev and Krasilnikova, 1994). Assuming spherical symmetry the bending angles $\alpha(a)$ (a: impact parameter) can be related to the refractive index $n$ (Fjeldbo et al., 1971):

$\alpha(a)=-2 a \int_{a}^{\infty} d a^{\prime}\left(\frac{1}{\sqrt{a^{\prime 2}-a^{2}}} \cdot \frac{d \ln n}{d a^{\prime}}\right)$ with $n=n(r)$ 
Equation (1) can then be inverted by using an Abel transform to express the refractive index $n$ in terms of the bending angle $\alpha$ and impact parameter $a$ (Fjeldbo et al., 1971):

$$
\ln n=\frac{1}{\pi} \int_{a}^{\infty} d a^{\prime} \frac{\alpha\left(a^{\prime}\right)}{\sqrt{a^{\prime 2}-a^{2}}} .
$$

The atmospheric refractivity $N(r)$ is given by using the formula from Smith and Weintraub (1953):

$$
N(r)=(n-1) \cdot 10^{6}=77.6 \frac{p}{T}+3.73 \cdot 10^{5} \frac{e_{w}}{T^{2}}
$$

(with $p$ : air pressure, $T$ : air temperature, and $e_{w}$ : water vapor pressure). $N(r)$ is the basic meteorological observable determined by the GPS RO technique.

To convert the refractivity profiles into pressure and temperature profiles the assumption of dry air has to be made because of the ambiguity between the dry and wet part in the resulting refractivity profile (Eq. (3)). Since the saturation water vapor pressure decreases with decreasing temperature, water vapor in the troposphere can be ignored if the temperature is below $250 \mathrm{~K}$ (Kursinski et al., 1997). The hydrostatic equation is used to calculate pressure and temperature profiles. In the current retrieval version 005 (Wickert et al., 2004a) ECMWF pressure at $43 \mathrm{~km}$ is used for the initialisation of the hydrostatic equation. This is one atmospheric scale height above the upper level for which profile data are provided $(35 \mathrm{~km})$. As shown by Hajj et al. (2004) there is nearly no difference between the initialisation of the hydrostatic equation with ECMWF data at 32,35 , and $40 \mathrm{~km}$ for heights below $20 \mathrm{~km}$.

The vertical resolution of an occultation measurement is determined by the contribution of individual atmospheric layers to net bending along the ray path (Eq. (1)). As discussed in Kursinski et al. (1997) by using the geometrical optics approach the vertical resolution is limited by the diameter of the first Fresnel zone $z_{F}$. For the CHAMP orbit geometry $z_{F}$ is about $1.4 \mathrm{~km}$ in the stratosphere (about $270 \mathrm{~km}$ horizontal resolution). Because of the exponential increase of the refractivity towards the Earth's surface $z_{F}$ decreases to about $0.5 \mathrm{~km}$ (horizontal resolution about $80 \mathrm{~km}$ ). Considering diffraction effects and applying wave optical methods as, e.g., the Full Spectrum Inversion (FSI) method (Jensen et al., 2003) the vertical resolution can be improved significantly (to about $50 \mathrm{~m}$ ). In our current software version (005) we have implemented both, the geometrical optics approach for heights above $15 \mathrm{~km}$ and the FSI method for heights below $10 \mathrm{~km}$. In the transition zone from $10-15 \mathrm{~km}$ a combination of both is used. This results in a physical vertical resolution of less than $1 \mathrm{~km}$ in the extra-tropical tropopause region. For the tropical tropopause region, where tropopause heights usually reach $16-18 \mathrm{~km}$, the vertical resolution is about $1 \mathrm{~km}$. For data provision all data were interpolated between the lowest level and $35 \mathrm{~km}$ with a vertical resolution of $200 \mathrm{~m}$.

It should be noted here that all profiles used in this study are results from data processing with a consistent software
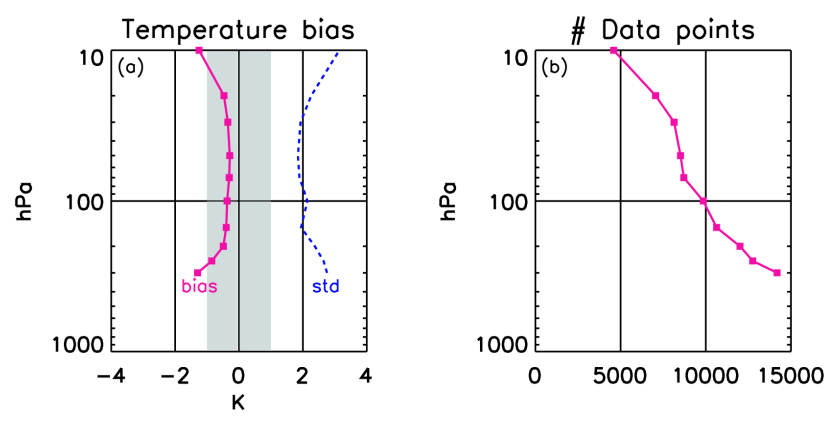

Fig. 2. Comparison of CHAMP temperature data with nearby radiosondes (distance $\Delta \mathrm{d} \leq 300 \mathrm{~km}$ and time delay $\Delta \mathrm{t} \leq 3 \mathrm{~h}$ ) for the period May 2001-September 2004. The dashed lines denote the standard deviation whereas the shaded area shows the $\pm 1 \mathrm{~K}$ interval.

version. Also the CHAMP/SAC-C and GPS orbits are generated by GFZ (König et al., 2005).

\subsection{Validation of CHAMP/SAC-C temperature data}

Before applying algorithms for the determination of LRT parameters the quality of CHAMP temperature data has to be discussed. Figure 2 shows a comparison of CHAMP RO temperatures with nearby radiosondes. About 10000 RO profiles reaching the $100-\mathrm{hPa}$ level meet the condition that the radiosonde was launched within a distance of less than $300 \mathrm{~km}$ and with a time delay less than $3 \mathrm{~h}$ from the CHAMP measurement. The comparisons with this independent radiosonde data show a temperature bias less than $1.5 \mathrm{~K}$ for the complete height interval between 300 and $10 \mathrm{hPa}$ with a standard deviation of 2-3 K (Fig. 2a). Between 200-20 hPa the bias is even less than $0.5 \mathrm{~K}$ ( $2 \mathrm{~K}$ standard deviation). The cold bias in the middle and lower troposphere (below $300 \mathrm{hPa}$ ) is caused by the difference between temperature and dry temperature for non-zero humidity (Kursinski et al., 1997). A more detailed validation study for comparisons of CHAMP and radiosonde temperature data is presented by Wickert (2004b). The author discusses the influence of different types of radiosondes used from different meteorological services on the results of the temperature comparisons and shows that the best agreement between $500-10 \mathrm{hPa}$ is achieved over Australia, Europe, Japan, and the USA. A similar study was performed by Kuo et al. (2005). A cross-validation of MIPAS/ENVISAT and CHAMP RO temperature profiles for 2 weeks in September/October 2002 shows global mean differences averaged between 8 and $30 \mathrm{~km}$ of less than $0.1 \mathrm{~K}$ (Wang et al., 2004). For the data quality of SAC-C temperature we refer to an intercomparison study for CHAMP and SAC-C (Hajj et al., 2004) that showed for nearby profiles (distance $\Delta \mathrm{d} \leq 200 \mathrm{~km}$ and time delay $\Delta \mathrm{t} \leq 30 \mathrm{~min}$ ) an agreement within $0.1 \mathrm{~K}$ in the mean between 5 and $15 \mathrm{~km}$ altitude. Individual comparisons have shown best agreement near the tropopause. 
Table 1. Mean differences and standard deviations between CHAMP/SAC-C and ECMWF LRT pressure, altitude, and temperature based on the period from May 2001-December 2004.

\begin{tabular}{lrrrr}
\hline Season & \multicolumn{1}{c}{ LRT pressure } & \multicolumn{1}{c}{ LRT altitude } & LRT temperature & Number of data \\
\hline NH winter & $(-3.4 \pm 37.0) \mathrm{hPa}$ & $(65 \pm 1147) \mathrm{m}$ & $(-0.2 \pm 4.0) \mathrm{K}$ & 32826 \\
NH summer & $(0.1 \pm 40.8) \mathrm{hPa}$ & $(-42 \pm 1229) \mathrm{m}$ & $(0.3 \pm 4.9) \mathrm{K}$ & 4253 \\
All & $(-2.1 \pm 37.1) \mathrm{hPa}$ & $(19 \pm 1143) \mathrm{m}$ & $(0.1 \pm 4.2) \mathrm{K}$ & 167699 \\
\hline
\end{tabular}

Table 2. Mean differences and standard deviations (LRT pressure and temperature) between CHAMP/SAC-C and nearby operational radiosondes $(\Delta \mathrm{d} \leq 300 \mathrm{~km}, \Delta \mathrm{t} \leq 3 \mathrm{~h})$ for the period May 2001September 2004.

\begin{tabular}{rccr}
\hline \multicolumn{1}{c}{ Season } & $\begin{array}{c}\text { LRT } \\
\text { pressure }\end{array}$ & $\begin{array}{c}\text { LRT } \\
\text { temperature }\end{array}$ & $\begin{array}{r}\text { Number } \\
\text { of data }\end{array}$ \\
\hline NH winter & $(6.6 \pm 20.1) \mathrm{hPa}$ & $(-0.1 \pm 3.7) \mathrm{K}$ & 2966 \\
NH summer & $(4.6 \pm 18.7) \mathrm{hPa}$ & $(-0.3 \pm 3.6) \mathrm{K}$ & 3161 \\
All & $(5.8 \pm 19.8) \mathrm{hPa}$ & $(-0.1 \pm 3.3) \mathrm{K}$ & 13230 \\
\hline
\end{tabular}

Table 3. Mean differences and standard deviations (LRT pressure and temperature) between CHAMP/SAC-C and nearby operational radiosondes ( $\Delta \mathrm{d} \leq 300 \mathrm{~km}, \Delta \mathrm{t} \leq 3 \mathrm{~h})$ at different latitude intervals for the period May 2001-September 2004.

\begin{tabular}{rrrr}
\hline Latitude & $\begin{array}{r}\text { LRT } \\
\text { pressure }\end{array}$ & $\begin{array}{r}\text { LRT } \\
\text { temperature }\end{array}$ & $\begin{array}{r}\text { Number } \\
\text { of data }\end{array}$ \\
\hline All & $(5.8 \pm 19.8) \mathrm{hPa}$ & $(-0.1 \pm 3.3) \mathrm{K}$ & 13230 \\
$60^{\circ} \mathrm{N}-90^{\circ} \mathrm{N}$ & $(5.2 \pm 20.8) \mathrm{hPa}$ & $(-0.5 \pm 3.6) \mathrm{K}$ & 3241 \\
$30^{\circ} \mathrm{N}-60^{\circ} \mathrm{N}$ & $(6.4 \pm 19.8) \mathrm{hPa}$ & $(-0.1 \pm 3.2) \mathrm{K}$ & 7794 \\
$30^{\circ} \mathrm{S}-30^{\circ} \mathrm{N}$ & $(2.3 \pm 14.6) \mathrm{hPa}$ & $(0.4 \pm 4.1) \mathrm{K}$ & 1071 \\
$30^{\circ} \mathrm{S}-60^{\circ} \mathrm{S}$ & $(4.6 \pm 20.0) \mathrm{hPa}$ & $(-0.1 \pm 3.1) \mathrm{K}$ & 571 \\
$60^{\circ} \mathrm{S}-90^{\circ} \mathrm{S}$ & $(7.5 \pm 21.9) \mathrm{hPa}$ & $(-0.1 \pm 2.7) \mathrm{K}$ & 565 \\
\hline
\end{tabular}

In addition to the pure temperature comparison Tables 1-3 show the differences in LRT parameters between GPS RO and ECMWF and radiosondes, respectively. The tropopause parameters from the radiosondes are taken from the operational network, whereas the tropopause level for the CHAMP/SAC-C and ECMWF data were determined by the algorithms described in Sect. 4. In the overall data there is a small negative (positive) LRT pressure bias between GPS RO and ECMWF (radiosondes), whereas nearly no LRT temperature bias exists. As shown in Tables 1 and 2 the standard deviation in both, the LRT pressure and temperature, is smaller between GPS RO and radiosondes than between GPS RO and ECMWF, especially for the LRT pressure. Table 3 shows the LRT pressure and temperature differences between CHAMP/SAC-C and nearby radiosondes for different latitude intervals with smallest LRT pressure bias and standard deviation in the tropics. The LRT temperature bias varies between -0.5 and $0.4 \mathrm{~K}$, with a standard deviation of 3-4 K. A detailed discussion of LRT differences between CHAMP/SAC-C and ECMWF follows in Sect. 5.2.4. When considering the differences from LRT parameters between GPS RO and ECMWF/radiosondes one should keep in mind that also different algorithms for their determination can lead to differences in LRT pressure and temperature.

\section{The data base}

Because of the similar quality of CHAMP and SAC-C temperature data as shown in Sect. 2.2 no difference is made between both data sets in the following. For the presentation of global statistics the Earth was divided into a regular grid of $18 \times 24$ cells, i.e., 18 latitude intervals centered at $85^{\circ} \mathrm{N}$, $\ldots, 85^{\circ} \mathrm{S}$ with a step width of $10^{\circ}$ and 24 longitude intervals centered at $0^{\circ}, 15^{\circ} \mathrm{E}, \ldots, 15^{\circ} \mathrm{W}$ with widths of $15^{\circ}$. Figure 3 shows the number of CHAMP/SAC-C data for the NH winter and NH summer months. NH winter (Southern Hemisphere (SH) summer) refers to December-February, whereas NH summer (SH winter) refers to June-August, respectively. For each bin averages of LRT pressure, altitude, temperature, potential temperature, and sharpness were computed, whereas no interpolation was necessary between neighboring bins. For the complete period of available CHAMP and SAC-C data a number of 177115 temperature profiles is available where the LRT parameters could be successfully determined. The further discussion is mainly focused on the data of the $\mathrm{NH}$ winter and summer season.

\section{Thermal tropopause and sharpness determination}

The LRT from CHAMP/SAC-C temperature data and ECMWF operational analyses was computed using the definition according to the WMO criteria (WMO, 1957). Here the tropopause is defined as "the lowest level at which the lapse-rate decreases to $2^{\circ} \mathrm{C} / \mathrm{km}$ or less, provided that the averaged lapse-rate between this level and all higher levels within $2 \mathrm{~km}$ does not exceed $2^{\circ} \mathrm{C} / \mathrm{km}$ ". The ECMWF temperature profiles were obtained by interpolating the 6-hourly operational ECMWF data sets (60 pressure levels) to the time 

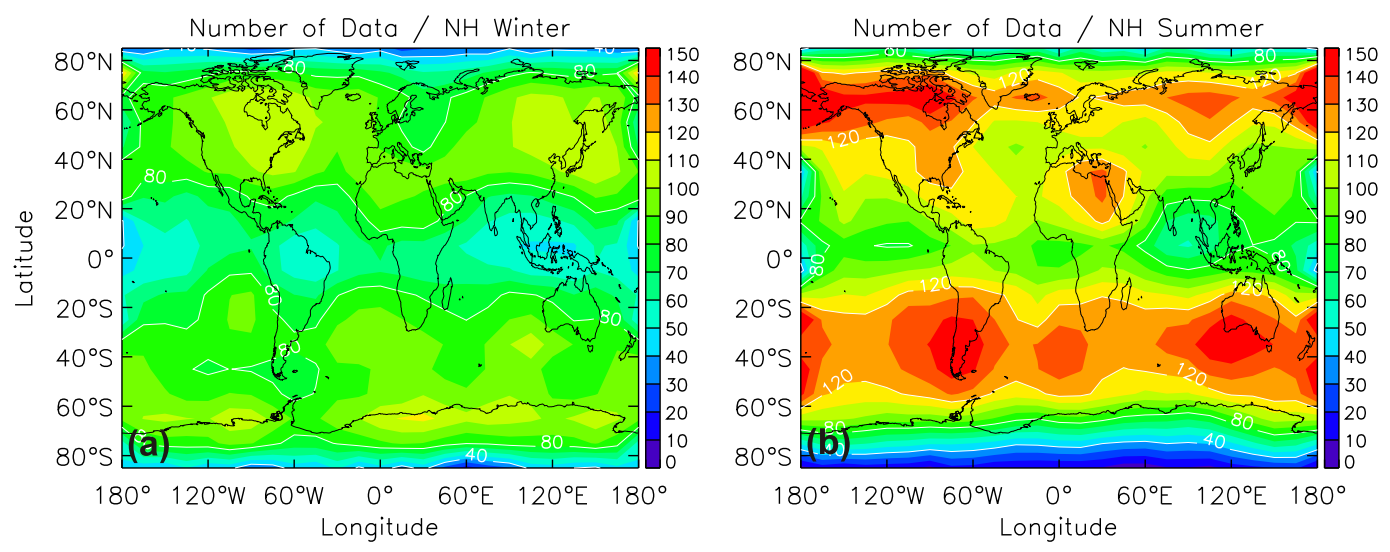

Fig. 3. Number of GPS RO for the NH winter (a) and summer (b) months for the period May 2001-December 2004.

of the occultation. Only the first LRT of each temperature profile was calculated, any LRT above was ignored. The LRT pressure and temperature data from the radiosonde network were taken from the coded operational data message. Because the vertical resolution of the GPS RO and ECMWF data differs, two different algorithms for the determination of the LRT were applied.

For the GPS RO data the algorithm works as follows. The lapse-rate was calculated between $500-70 \mathrm{hPa}$, starting at the lowest level, whereas a minimum altitude of $8 \mathrm{~km}(4 \mathrm{~km})$ was postulated between $40^{\circ} \mathrm{S}-40^{\circ} \mathrm{N}$ (outside $40^{\circ} \mathrm{S}-40^{\circ} \mathrm{N}$ ):

$\Gamma\left(z_{i}\right)=-\frac{\delta T}{\delta z}=\frac{T_{i+1}-T_{i}}{z_{i+1}-z_{i}}$.

$\mathrm{T}$ and $\mathrm{z}$ are the temperatures and geopotential heights, respectively. If $\Gamma\left(z_{i}\right)>\Gamma_{W M O}$, with $\Gamma_{W M O}=-2 \mathrm{~K} / \mathrm{km}$, the following conditions were checked: is the mean lapse-rate from all intervals between $z_{i}$ and $z_{i}+2 \mathrm{~km}$ greater than $\Gamma_{W M O}$ ? If not, it was jumped to the next lapse-rate. If yes, both of the following conditions are required around the possible tropopause height: none of the layers $\left\langle z_{i+1}, z_{i}\right\rangle$, $<z_{i+2}, z_{i}>$, and $<z_{i+3}, z_{i}>$ is allowed to have a lapse-rate less than $\Gamma_{W M O}$, whereas the mean lapse-rate from the layers $<z_{i}, z_{i-1}>,<z_{i-1}, z_{i-2}>$, and $<z_{i-2}, z_{i-3}>$ must be less than $\Gamma_{W M O}$. This minimises the influence of outliers in the temperature profile. If both conditions are fulfilled the LRT is found and altitude, pressure, and temperature are taken from $z_{i}$.

Due to the poorer vertical resolution of the ECMWF data compared to GPS RO a different algorithm is used for the determination of the LRT. As for the GPS RO data, first the lapse-rate is determined according Eq. 4 between 500$70 \mathrm{hPa}$. For every lapse-rate at $z_{i}$ the following conditions were checked: (1) The mean lapse-rate from all intervals between $z_{i}$ and $z_{i}+2 \mathrm{~km}$ is greater than $\Gamma_{W M O}$, and (2) no single layer between $z_{i}$ and $z_{i}+2 \mathrm{~km}$ exist where the lapserate is less than $\Gamma_{W M O}$. The LRT is the intersection of two

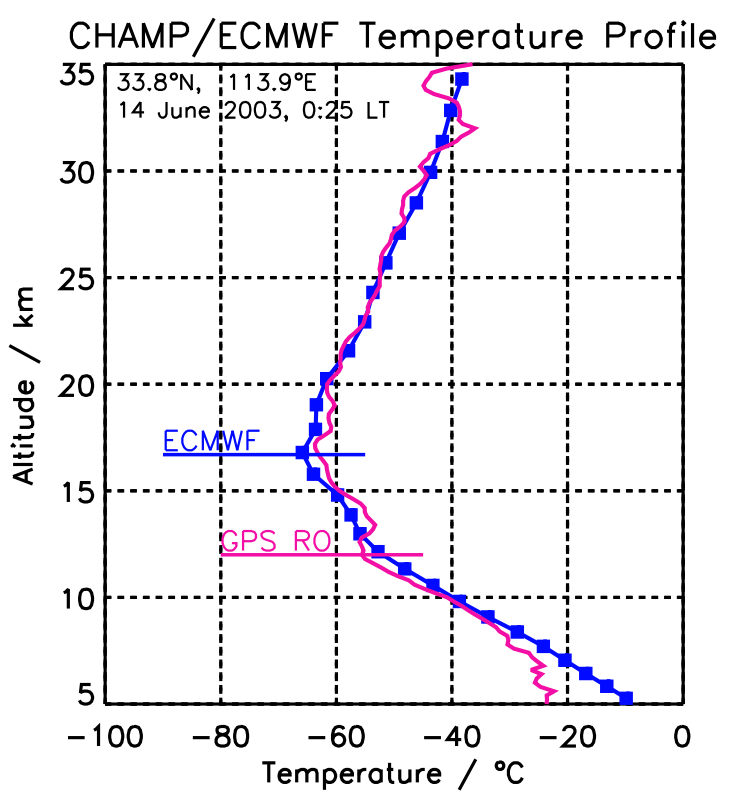

Fig. 4. Comparison of CHAMP and ECMWF temperature profile and deduced lapse-rate tropopause.

regression lines using the data points $\left\langle z_{i}, z_{i+1}, z_{i+2}, z_{i+3}>\right.$ from above and $<z_{i}, z_{i-1}, z_{i-2}, z_{i-3}>$ below.

To avoid unrealistic LRT altitudes in polar regions (latitude $>70^{\circ}$ on both hemispheres) especially during the polar night months, in addition to the pressure criteria (500-70 hPa) all LRT from GPS RO and ECMWF were removed if the temperature at the LRT was below $-70^{\circ} \mathrm{C}$.

The sharpness of the tropopause (Wirth, 2000) that quantifying the change in vertical temperature gradient across the tropopause is determined following an algorithm by Birner (2003). From the LRT altitude level $z_{T}$ the mean lapserate is computed $1 \mathrm{~km}$ above $\left(\Gamma_{+}\right)$and below $\left(\Gamma_{-}\right) z_{T P}$ by the slope of the regression line including all data points 
LRT Altitude Frequency Distribution $70^{\circ} \mathrm{N}-90^{\circ} \mathrm{N}$

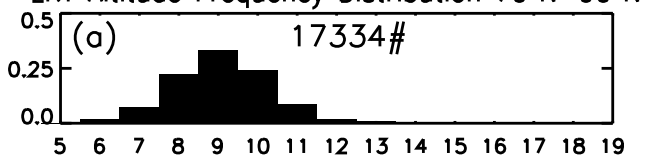

LRT Altitude Frequency Distribution $30^{\circ} \mathrm{N}-50^{\circ} \mathrm{N}$

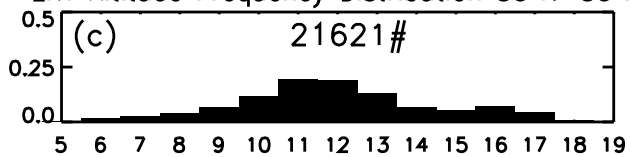

LRT Altitude Frequency Distribution $10^{\circ} \mathrm{S}-10^{\circ} \mathrm{N}$

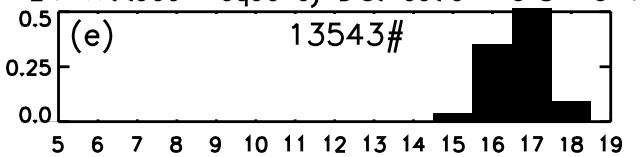

LRT Altitude Frequency Distribution $30^{\circ} \mathrm{S}-50^{\circ} \mathrm{S}$

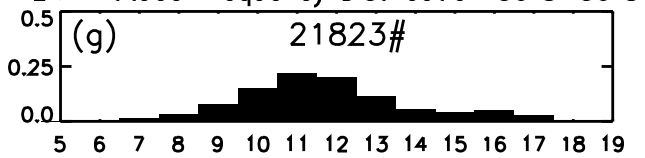

LRT Altitude Frequency Distribution $70^{\circ} \mathrm{S}-90^{\circ} \mathrm{S}$

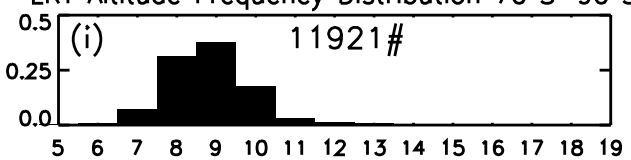

LRT Altitude Frequency Distribution $50^{\circ} \mathrm{N}-70^{\circ} \mathrm{N}$

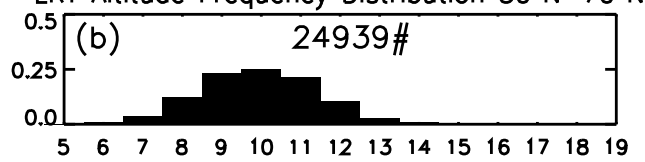

LRT Altitude Frequency Distribution $10^{\circ} \mathrm{N}-30^{\circ} \mathrm{N}$

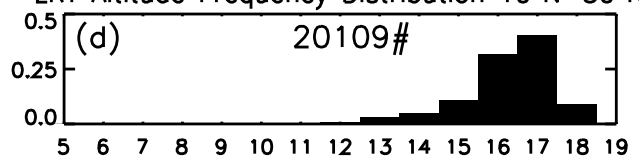

LRT Altitude Frequency Distribution $10^{\circ} \mathrm{S}-30^{\circ} \mathrm{S}$

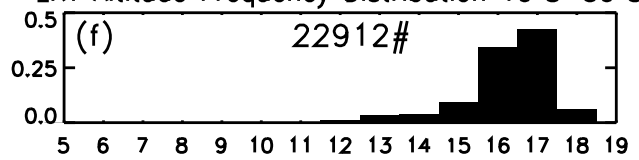

LRT Altitude Frequency Distribution $50^{\circ} \mathrm{S}-70^{\circ} \mathrm{S}$
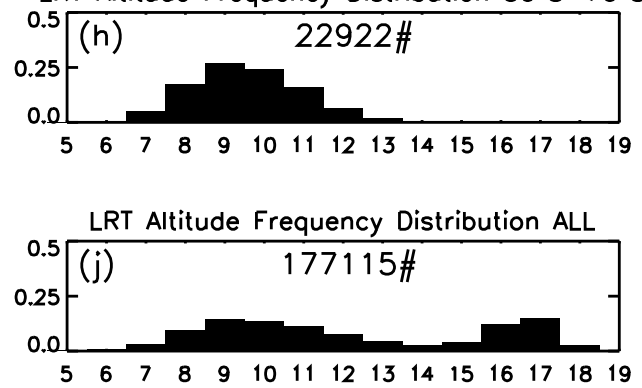

Fig. 5. Frequency distribution of all GPS RO LRT altitudes from different latitude intervals and the period May $2001-D e c e m b e r 2004$.

between $z_{T P}+1 \mathrm{~km}$ and $z_{T P}-1 \mathrm{~km}$, respectively. The normalised sharpness $\mathrm{S}$ results to:

$S=\frac{\Gamma_{+}-\Gamma_{-}}{\Gamma_{\text {strat }}-\Gamma_{\text {trop }}}=\frac{\Gamma_{+}-\Gamma_{-}}{6.5}$

with the mean lapse-rates for the lower stratosphere $\Gamma_{\text {strat }}=0 \mathrm{~K} / \mathrm{km}$ and upper troposphere $\Gamma_{\text {trop }}=-6.5 \mathrm{~K} / \mathrm{km}$ from the US standard atmosphere (NOAA/NASA/USAF, 1976), respectively.

Figure 4 shows an example of the determination of the LRT from CHAMP and ECMWF data. It is also an example that points out the differences in LRT caused by different vertical resolution. This discussion is continued in Sect. 5.2.4.

\section{The global thermal tropopause from GPS RO}

The tropopause separates the troposphere and stratosphere that have fundamentally different characteristics with respect to chemical composition and static stability. As mentioned in Sect. 1 tropopause parameters, especially the tropopause height and pressure, have received attention in recent years for describing climate variability (Sausen and Santer, 2003;
Santer et al., 2004). On the other hand dynamical, chemical, and radiative coupling between the stratosphere and troposphere are among the many important processes that must be understood for the stratosphere-troposphere exchange (Holton et al., 1995; Schoeberl, 2004). This is a reason for the continuous identification and monitoring of the tropopause on a global scale and an important goal in atmospheric and climate research. This can be performed by the RO technique due to its high vertical resolution and global coverage, but it is limited to the determination of the thermal tropopause.

For the tropopause several definitions have been introduced. By using the lapse-rate criteria (WMO, 1957) the thermal tropopause is given, the potential vorticity (Holton et al., 1995) is used to define the dynamical tropopause, whereas ozone gradients can also serve for defining the tropopause level. As discussed in Highwood and Hoskins (1998) the LRT has limited physical relevance especially in the tropics. They argued that there is little direct connection between convective processes and the LRT definition. The temperature minimum or cold-point tropopause (CPT) becomes more important for describing tropical tropopause characteristics because these correlate better with convective 

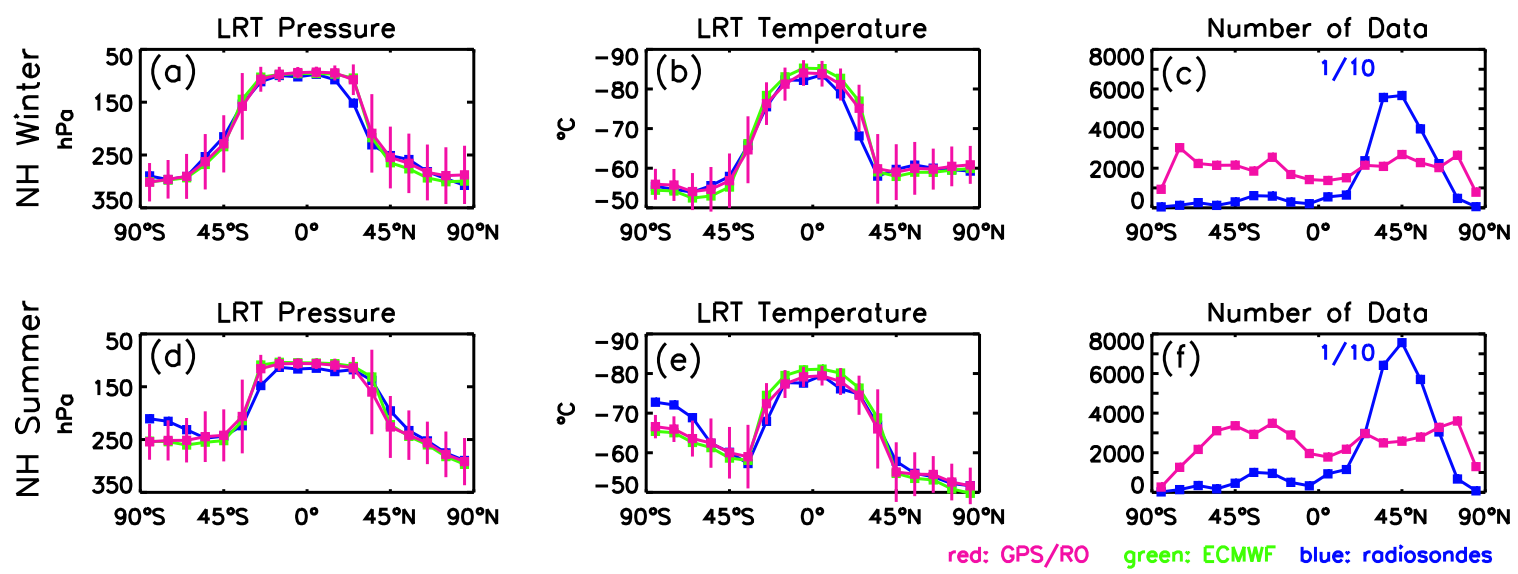

Fig. 6. Zonal means and standard deviation of LRT parameters from CHAMP/SAC-C for the period May 2001-December 2004 in comparison with ECMWF and radiosondes.

processes that play an important role in the stratospheretroposphere exchange. Gettelman and de Forster (2002) suggest that the CPT forms the upper boundary of the so-called tropical transition layer (TTL). A general problem is the determination of the LRT in the extra-tropics, especially at high latitudes during winter (Highwood et al., 2000).

However, as pointed out by Pan et al. (2004) the differences between the thermal and dynamical tropopause definition is caused by the difference in the underlying concepts. The LRT gives the location of the transition point in the vertical thermal structure between troposphere and stratosphere. The dynamical tropopause serves to locate a quasi-material surface for the identification of the chemical transition from stratosphere to troposphere.

Therefore, the choice of tropopause definition depends on the question, which is to be examined. Because LRT pressure or altitude are parameters for detection of climate change (Sausen and Santer, 2003; Santer et al., 2004) the GPS RO could play an important role in global monitoring of the LRT. In this study we demonstrate the potential for this by presenting global LRT parameters from CHAMP/SAC-C for the period May 2001-December 2004 and compare them with radiosondes and ECMWF operational analyses.

\subsection{Tropopause meridional structure}

Figure 5 shows the frequency distribution of all CHAMP/SAC-C LRT altitudes for the period May 2001December 2004 divided into several latitude intervals. It shows relatively small ranges of LRT in the polar and tropical regions and nearly symmetric behavior between the Northern and Southern Hemisphere. An interesting feature is the bimodal distribution of the LRT altitude between $30^{\circ}-$ $50^{\circ}$ on both hemispheres. This includes the transition zone between the tropics and extra-tropics where the subtropical jet $(\mathrm{STJ})$ is located (around $30^{\circ}-35^{\circ}$ ). The jet stream is responsible for breaks in the thermal tropopause leading to multiple tropopauses as also seen in the example of Fig. 4. Because we only consider the first LRT the LRT altitude in this latitude interval $\left(30^{\circ}-50^{\circ}\right)$ depends on the location of the RO measurement with respect to the STJ. Most of the measurements in Fig. 5c were north of the STJ, whereas Fig. 5g suggests that most of the measurements were taken on the southern side of the STJ. A similar bimodal LRT distribution was found by Pan et al. (2004) from aircraft measurements with the Microwave Temperature Profiler (MTP) around $40^{\circ} \mathrm{N}$.

As seen in Fig. 6 the tropopause has a strong latitudinal dependence during both, $\mathrm{NH}$ winter and summer. In the tropics $\left(30^{\circ} \mathrm{S}-30^{\circ} \mathrm{N}\right)$ the tropopause pressure is nearly constant. In the deep tropics $\left(10^{\circ} \mathrm{S}-10^{\circ} \mathrm{N}\right)$ the LRT pressure reaches in the mean values as low as about $100 \mathrm{hPa}$. For a more detailed discussion of tropical LRT parameters from GPS RO we refer to Nishida et al. (2000), Randel et al. (2003), and Schmidt et al. (2004b). The strongest gradients in tropopause pressure occur between $30^{\circ}-60^{\circ}$ on both hemispheres. The LRT pressure is lower in summer than in winter time with largest differences in the Antarctic region. The standard deviation is biggest in the NH summer in the vicinity of the STJ (around $35^{\circ} \mathrm{N}$ ) with values reaching $80 \mathrm{hPa}$, and also in the Southern Hemisphere STJ region but with slightly lower values.

The seasonal mean meridional temperature pattern represents the corresponding tropopause pressure features (Figs. 6b, e). The lowest mean LRT temperatures are found in the deep tropics during $\mathrm{NH}$ winter reaching on average $-82^{\circ} \mathrm{C}$. The LRT temperature is lower during winter in all latitude intervals. The largest deviations occur in both, the Arctic and Antarctic region. The temperature standard deviation shows a similar picture as those for the LRT pressure with also largest values in the jet stream regions.

The asymmetric behavior between the Northern and Southern Hemisphere, especially seen in the LRT 

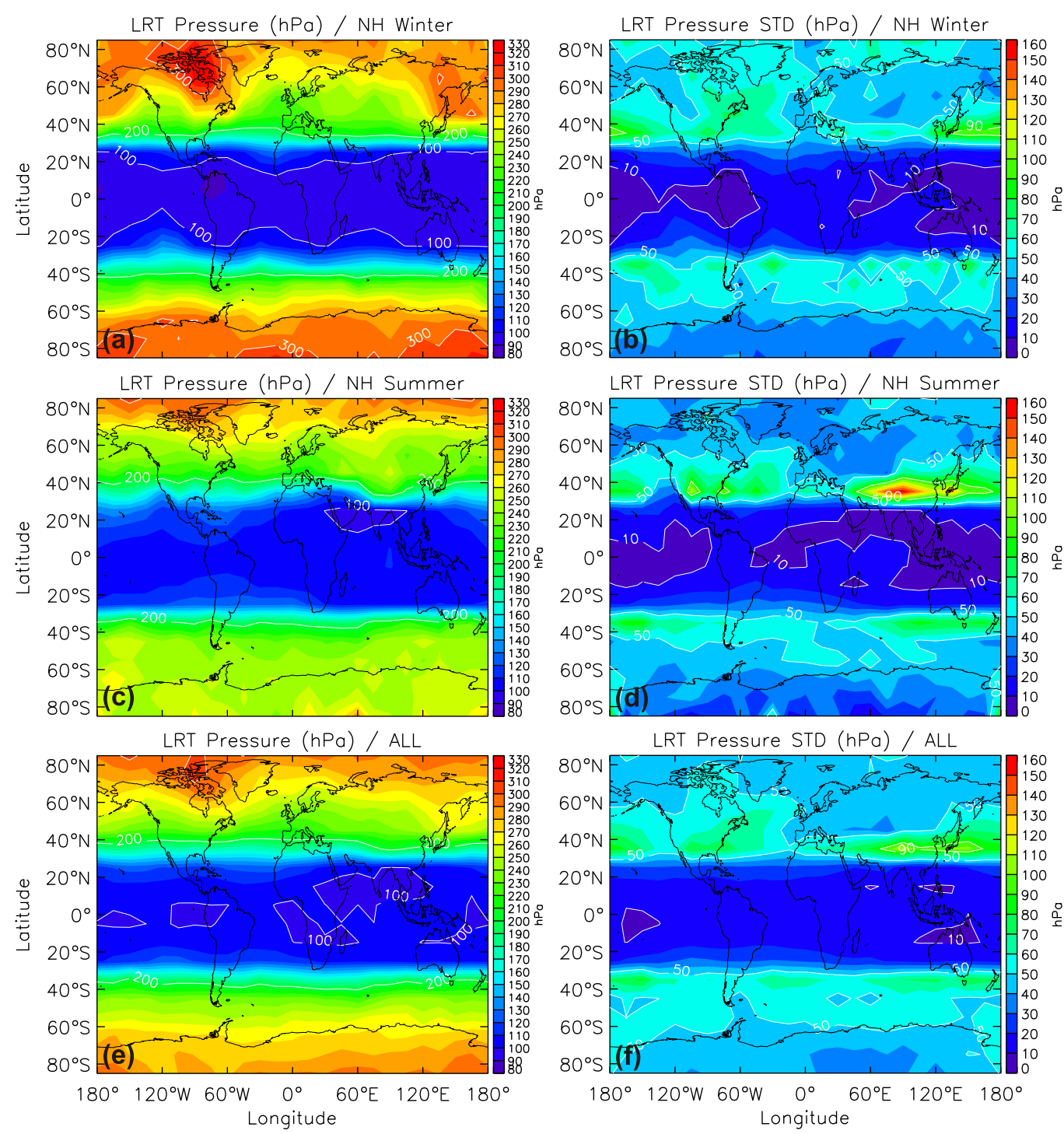

Fig. 7. Mean LRT pressure (a, c, e) and standard deviation (b, d, f) from CHAMP/SAC-C for the period May 2001-December 2004.

temperature (Figs. 6b, e) is caused by the different distribution of the land-see masses on both hemispheres resulting in different mean circulation characteristics.

In addition to the general meridional behavior of the LRT pressure and temperature Fig. 6 also shows a comparison of the derived GPS RO data with radiosonde measurements and ECMWF data. It should be noted here that only LRT parameters for CHAMP/SAC-C and ECMWF data are computed for the same time and location. The number of successfully determined tropopauses from ECMWF data at the location of the RO is 167699 . Radiosonde data were taken as they were available from the operational network mostly at 00:00 and 12:00 UTC and with the biggest number on the Northern Hemisphere (Figs. 6c, f). Nevertheless, Fig. 6 gives a general picture of the meridional agreement of LRT pressure and temperature between the three types of data. Largest deviations occur between $25^{\circ}-45^{\circ}$ on both hemispheres. The overall deviations between CHAMP/SAC-C and ECMWF and radiosondes are listed in Tables 1-3.

An interesting feature in Fig. 6 are the radiosonde LRT pressure and temperature values for the Antarctic region during SH winter. Both parameters are unrealistic. This is probably caused by the strict use of the WMO criteria for the LRT without a plausibility check within the operational radiosonde data software.

\subsection{Tropopause spatial structure}

The spatial, i.e. latitudinal-longitudinal, structure of the LRT derived from CHAMP/SAC-C RO measurements for the NH winter and summer months is shown in Figs. 7-9. 

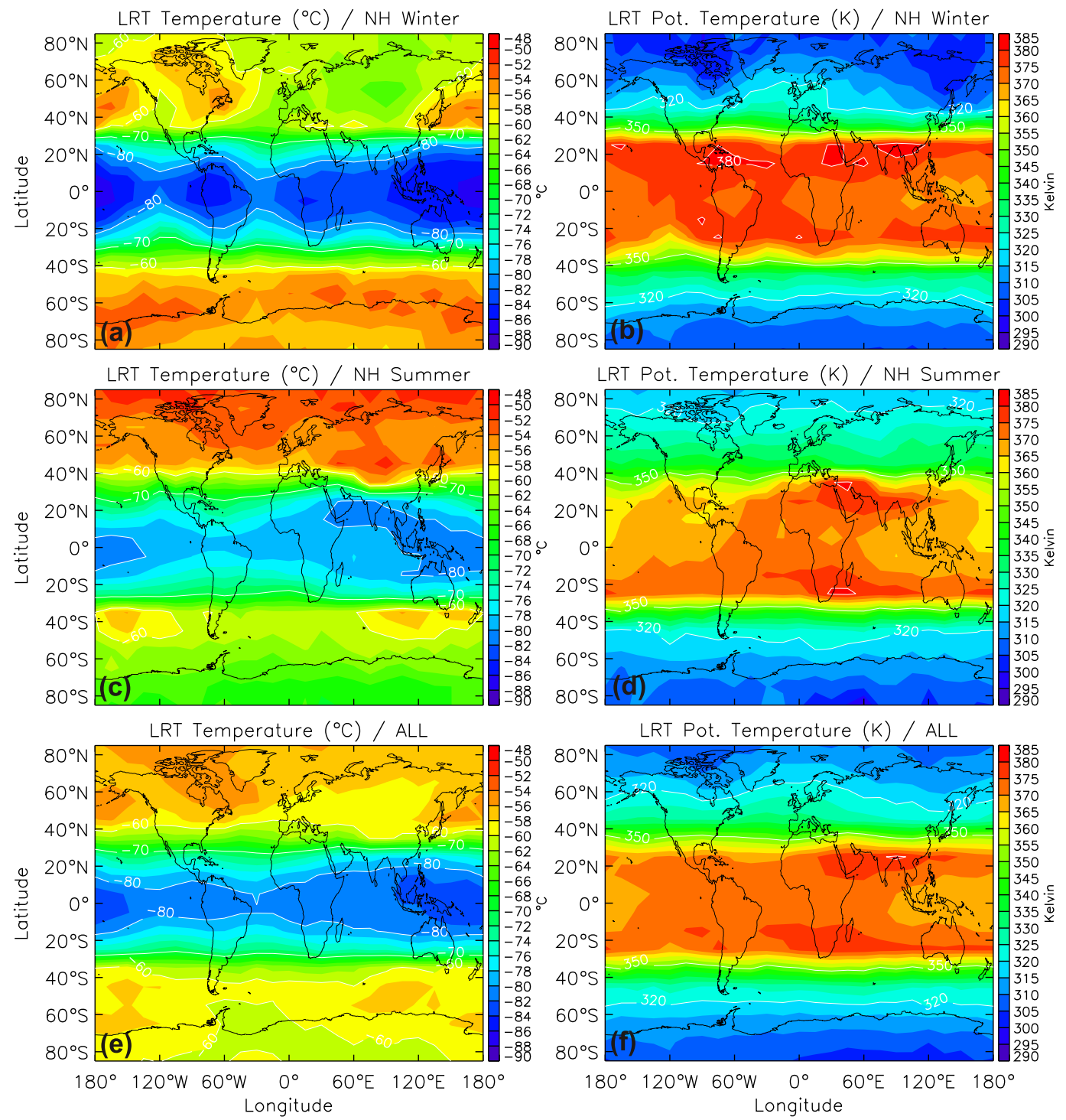

Fig. 8. Mean LRT temperature (a, c, e) and potential temperature (b, d, f) from CHAMP/SAC-C for the period May 2001-December 2004.

\subsubsection{Pressure}

Figures 7a-d show the global LRT pressure and standard deviation for the $\mathrm{NH}$ winter and summer, whereas Figs. 7e, $\mathrm{f}$ give an overall picture from mean LRT pressure and standard deviation for the complete time period. An almost uniform LRT pressure distribution is found over the tropics with little longitudinal and latitudinal variation during all times. A LRT pressure maximum is observed over North Canada/West Greenland with values reaching $320 \mathrm{hPa}$ during $\mathrm{NH}$ winter. A second maximum in NH winter over East Siberia/Western Pacific reaches $290-300 \mathrm{hPa}$. Similar maxima were found by Hoinka (1998) with the first more centered over Greenland $(300 \mathrm{hPa})$. The $300 \mathrm{hPa}$ value is also observed over Antarctica during SH summer. A sharp LRT pressure gradient is observed between $20^{\circ}-40^{\circ}$ on both hemispheres during all times. This strong isobars convergence is consistent with the mean location of the upper-level STJ. During winter on the Northern Hemisphere the strongest isobar convergence is found over the Western Pacific region. During summer the gradients are weaker, the strongest LRT pressure gradients are observed then over central and east Asia associated with the location of the inner-tropical convergence zone during the summer monsoon period. In the Southern Hemisphere strongest LRT pressure gradients occur also during winter. They are located over southern Australia and the western Pacific. The Southern Hemisphere LRT pressure has a more zonal characteristic, whereas the land-sea distribution on the Northern Hemisphere forms a wave pattern with wave numbers from 2-4 (Hoinka, 1998) that is more intensified during 

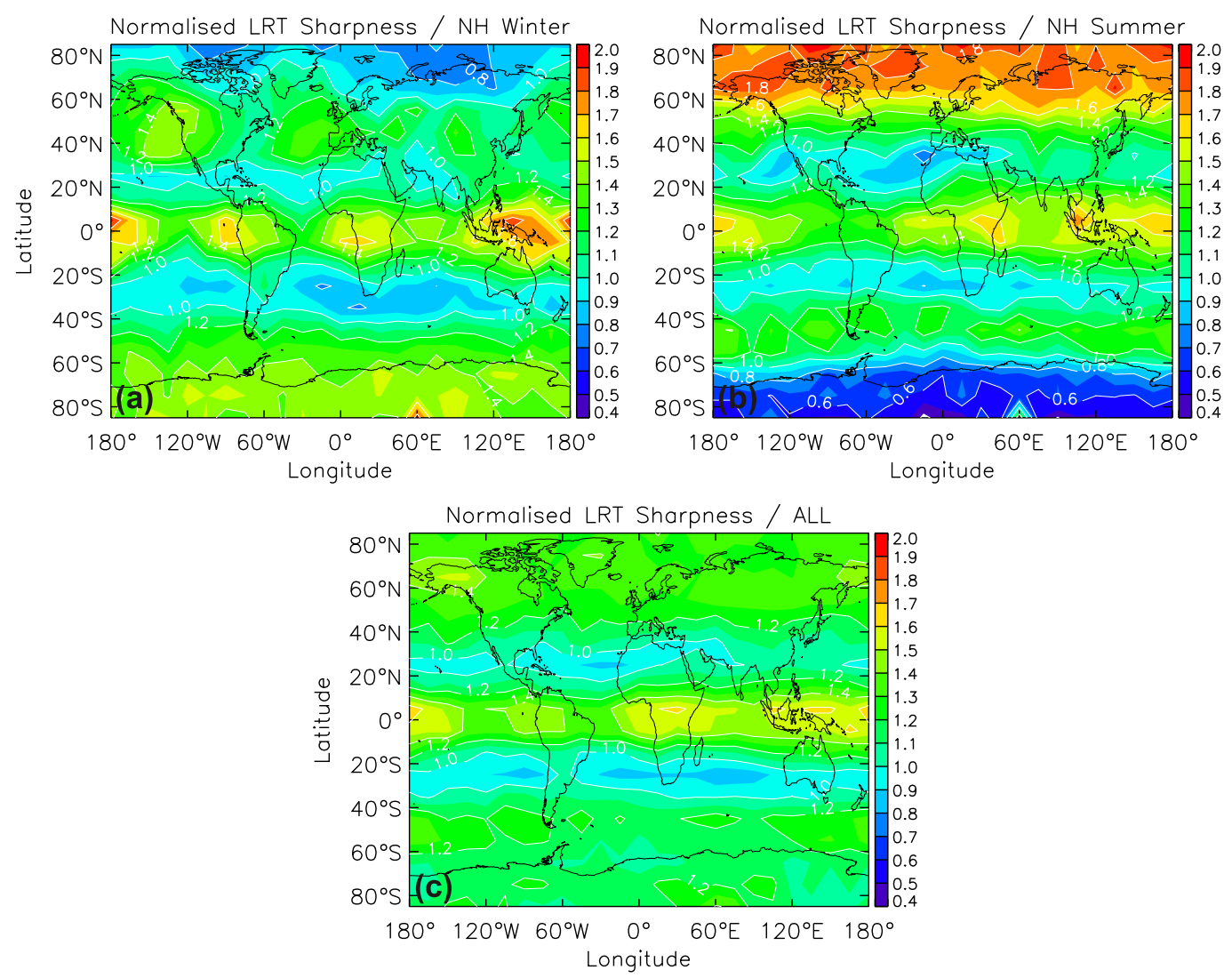

Fig. 9. Mean LRT sharpness from CHAMP/SAC-C for the period May 2001-December 2004.

$\mathrm{NH}$ winter. The zone of the strong pressure gradient is shifting north (south) during the summer months on the Northern (Southern) Hemisphere (Figs. 7a, c). On average this band is located around $35^{\circ}$ on both, the Northern and Southern Hemisphere (Fig. 7e).

Largest mean standard deviations for LRT pressure $(>100 \mathrm{hPa})$ are correlated with the areas of strongest LRT pressure gradients in the vicinity of the STJ (Figs. 7b, d, f). The lowest standard deviation during all seasons is seen in the tropics (10-20 hPa). During NH winter on the Northern Hemisphere the area of higher standard deviation is extended to the north (Fig. 7b). This coincides, especially in the north Atlantic, with the storm tracks regions. As also observed by Hoinka (1998) there is a maximum in standard deviation over the Tibetan plateau during NH summer (Fig. 7d) connected with the location of the inner-tropical convergence zone during the summer monsoon period. There is also a more zonal character of the standard deviation during all time in the Southern Hemisphere as already seen for the pressure.

\subsubsection{Temperature and potential temperature}

The global distribution of the LRT temperature (Figs. 8a, c, e) corresponds to the pressure distribution (Figs. 7a, c, e). The coldest LRT temperatures are found during $\mathrm{NH}$ winter in the tropics with values less than $-84^{\circ} \mathrm{C}$. In the western Pacific region tropopause temperatures of even less than $-86^{\circ} \mathrm{C}$ are reached. Within this so-called "warm pool region" of the western Pacific deep convection is the main feature leading to low tropopause temperatures (Highwood and Hoskins, 1998). On average a warm tropopause $\left(-58^{\circ} \mathrm{C}\right)$ is found over Canada in $\mathrm{NH}$ winter correlated to the high LRT pressure in that region. At the same time a $6 \mathrm{~K}$ colder tropopause is observed over central Siberia. A similar contrast in the Southern Hemisphere is not observed due to the more symmetric flow pattern in that region. The differences in LRT temperatures between Arctic and Antarctic regions are largest during NH summer with values of about $14 \mathrm{~K}$. This can be explained by the cold temperatures within the Antarctic polar vortex. Our estimate differs from Hoinka (1999) (8 K). The strongest temperature gradients are found in the vicinity of the STJ between $20^{\circ}-40^{\circ}$ on both hemispheres.

The potential temperature is defined as $\Theta=\mathrm{T}(1000 \mathrm{hPa} / \mathrm{p})^{k}$ (T, p: air temperature and pressure, respectively; $\kappa=0.286$ ) and is often used to locate the tropical tropopause (Holton et al., 1995). The results are presented in Figs. 8b, d, f. They show a strong meridional characteristic with mean values varying between $305 \mathrm{~K}$ in polar regions and $375-380 \mathrm{~K}$ 

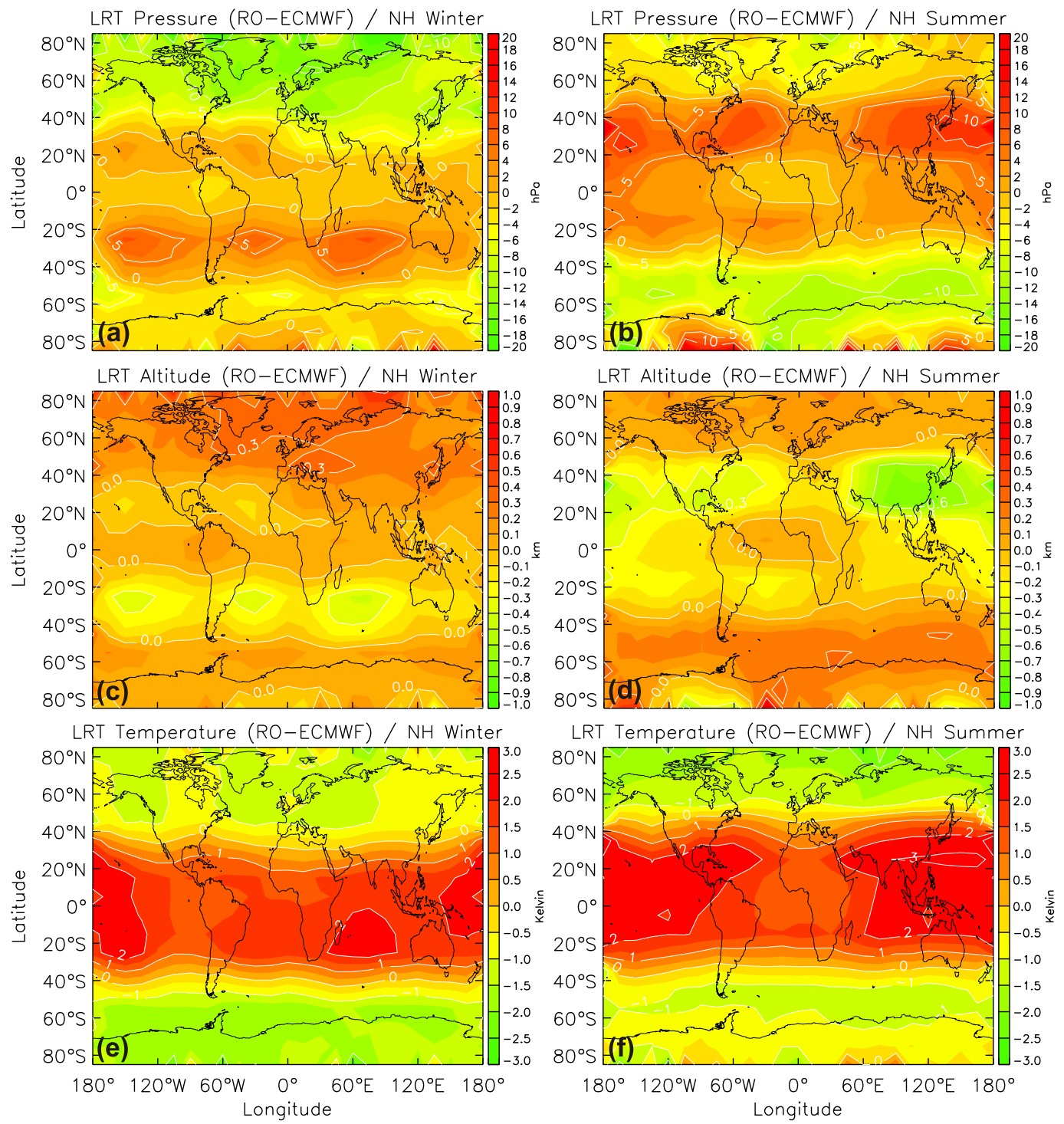

Fig. 10. Seasonal (winter, summer) mean LRT pressure $(\mathbf{a}, \mathbf{b})(\mathrm{hPa})$, altitude $(\mathbf{c}, \mathbf{d})(\mathrm{km})$ and temperature $(\mathbf{e}, \mathbf{f})(\mathrm{K})$ differences between GPS RO and ECMWF operational analyses (May 2001-December 2004).

in the tropics. There is almost no difference between Arctic and Antarctic region during NH Winter, but a difference of $10-15 \mathrm{~K}$ during June-August.

\subsubsection{Sharpness}

The tropopause sharpness was introduced in Sect. 4 as a measure of the change in vertical temperature gradient across the tropopause. This parameter allows for the quantification of the degree of separation between troposphere and stratosphere. Based on 10 years of radiosonde data for two stations at mid-latitudes Birner et al. (2002) have shown that a strong mean inversion at the tropopause with a vertical extension of $2 \mathrm{~km}$ and a temperature increase of $4 \mathrm{~K}$ exists. Figure 9 shows the global distribution of the LRT tropopause sharpness derived from GPS RO.

It is clearly seen that the sharpness is highest in the Arctic region during $\mathrm{NH}$ summer reaching values greater than 1.8 (Fig. 9b). A similar statement is true for Antarctica in $\mathrm{SH}$ summer but with lower values of about 1.5 (Fig. 9a). During the winter months the sharpness decreases to values less than 1 in the polar regions with a larger extent on the Southern Hemisphere (up to $60^{\circ} \mathrm{S}$ ). This is caused by the polar vortex during this time. The stronger and more symmetric vortex on the Southern Hemisphere causes the larger extent of the region with the weaker tropopause sharpness.

In the tropics the variation of the sharpness is less during the year compared with the polar regions. A maximum 

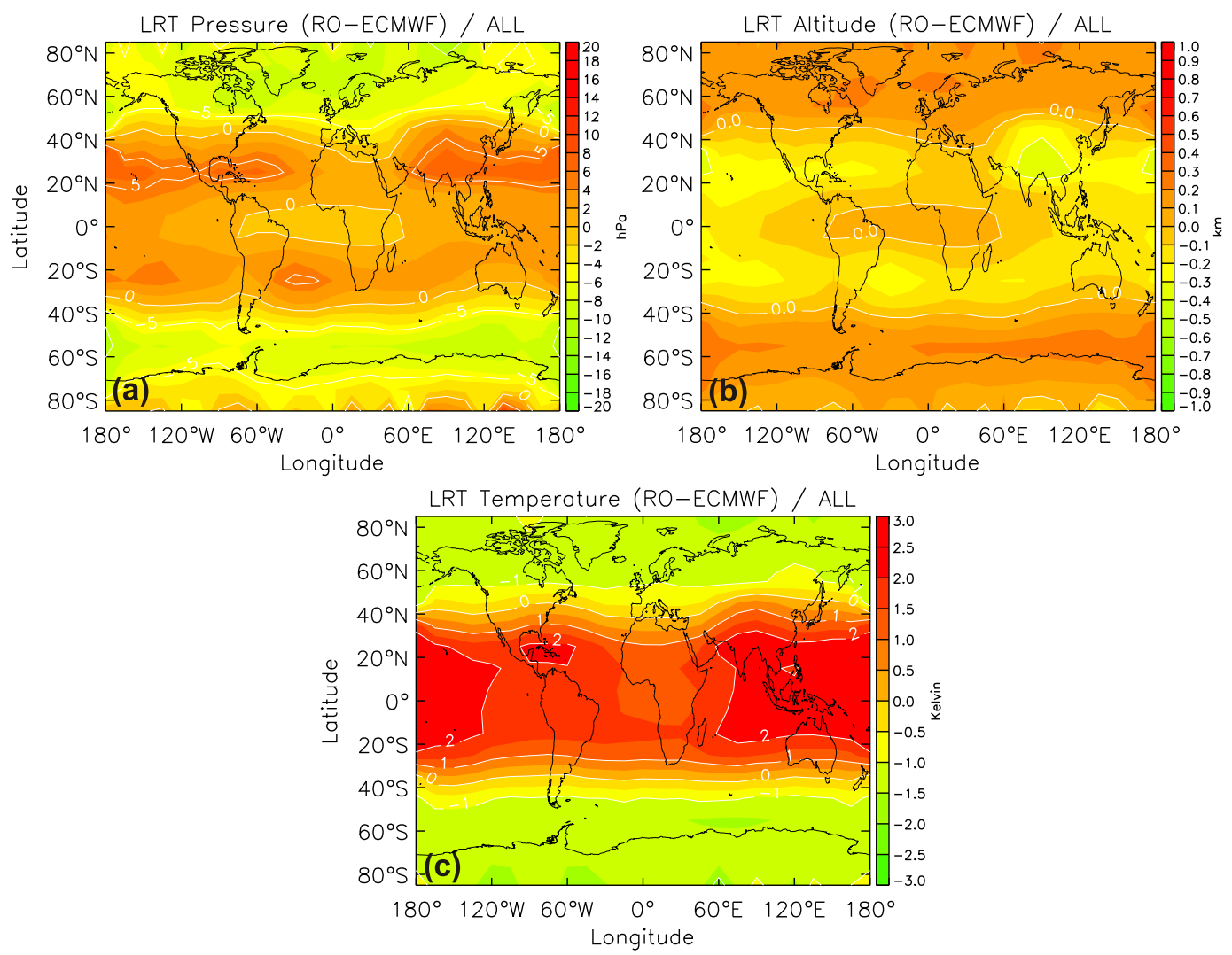

Fig. 11. Mean LRT pressure (hPa), altitude $(\mathrm{km})$ and temperature $(\mathrm{K})$ differences between GPS RO and ECMWF operational analyses for the complete time interval (May 2001-December 2004).

sharpness (1.6-1.8) all year long is observed over the western Pacific "warm pool" region with slightly higher values during $\mathrm{NH}$ winter. This is in agreement with lower tropopause pressure and temperature during that season compared with the summer months (Figs. 7a, c and Figs. 8a, c). The same is valid for central Africa and parts of South America.

High sharpness values $(>1.3)$ are found during $\mathrm{NH}$ winter between $40^{\circ} \mathrm{N}-60^{\circ} \mathrm{N}$ over the Atlantic and eastern Pacific (Fig. 9a). At this time in this regions low pressure systems are dominating. A similar, but smaller region is found at $\mathrm{SH}$ winter between $40^{\circ} \mathrm{S}-60^{\circ} \mathrm{S}$ around $180^{\circ}$ longitude (Fig. $9 \mathrm{~b}$ ). A sharpness less than 1 is observed in most parts of the STJ. Averaging over the complete time period the normalised sharpness is greater 1 with the exception of areas around $30^{\circ}$ (Fig. 9c) in the vicinity of the STJ. Highest values $(>1.5)$ are found over areas with large convection in the tropics.

Due to the normalization of the LRT sharpness with respect to the mean temperature lapse-rate in the upper troposphere and lower stratosphere (see Eq. 5) Fig. 9 shows also the deviation between the mean tropopause sharpness of the US standard atmosphere and GPS RO measurements. If the normalised sharpness is less than 1 it is lower than the sharpness of the standard atmosphere, in case of values above 1 it is larger, respectively. The latter is found on average (Fig. 9c) with only some exceptions in the STJ region.

\subsubsection{Comparison with ECMWF}

In this section we compare the LRT altitude and temperature derived from GPS RO with those from ECMWF operational analyses. Meridional differences between GPS RO and ECMWF were already shown in Fig. 6. Largest deviations in LRT pressure occur between $25^{\circ}-45^{\circ}$ on both hemispheres, whereas the overall deviations between CHAMP/SAC-C and ECMWF listed in Table 1 are relatively small. Seasonal and regional differences are shown in Figs. 10 and 11. It is clearly seen that on average GPS RO LRT pressure (altitude) is systematically higher (lower) in the vicinity of the STJ with highest values (by up to $>10 \mathrm{hPa}$ or $700 \mathrm{~m}$ ) over east Asia/western Pacific during NH summer. In the polar jet region on both hemispheres during the corresponding winter months GPS RO gives lower pressure (higher altitude) values than ECMWF by up to $-15 \mathrm{hPa}(300-400 \mathrm{~m})$ on the Northern Hemisphere. In the remaining areas the differences vary between about $\pm 6 \mathrm{hPa}$ ( $\pm 100 \mathrm{~m}$; Figs. 10a-d). This is also evident from the overall average (Figs. 11a, b).

The corresponding temperature deviations can be seen in Figs. 10e, $\mathrm{f}$ and $11 \mathrm{c}$. The maximum temperature deviation between GPS RO and ECMWF (about $2-3 \mathrm{~K}$ ) is observed south (north) of the maximum altitude deviation at the Northern (Southern) Hemisphere. This seems to be consistent 


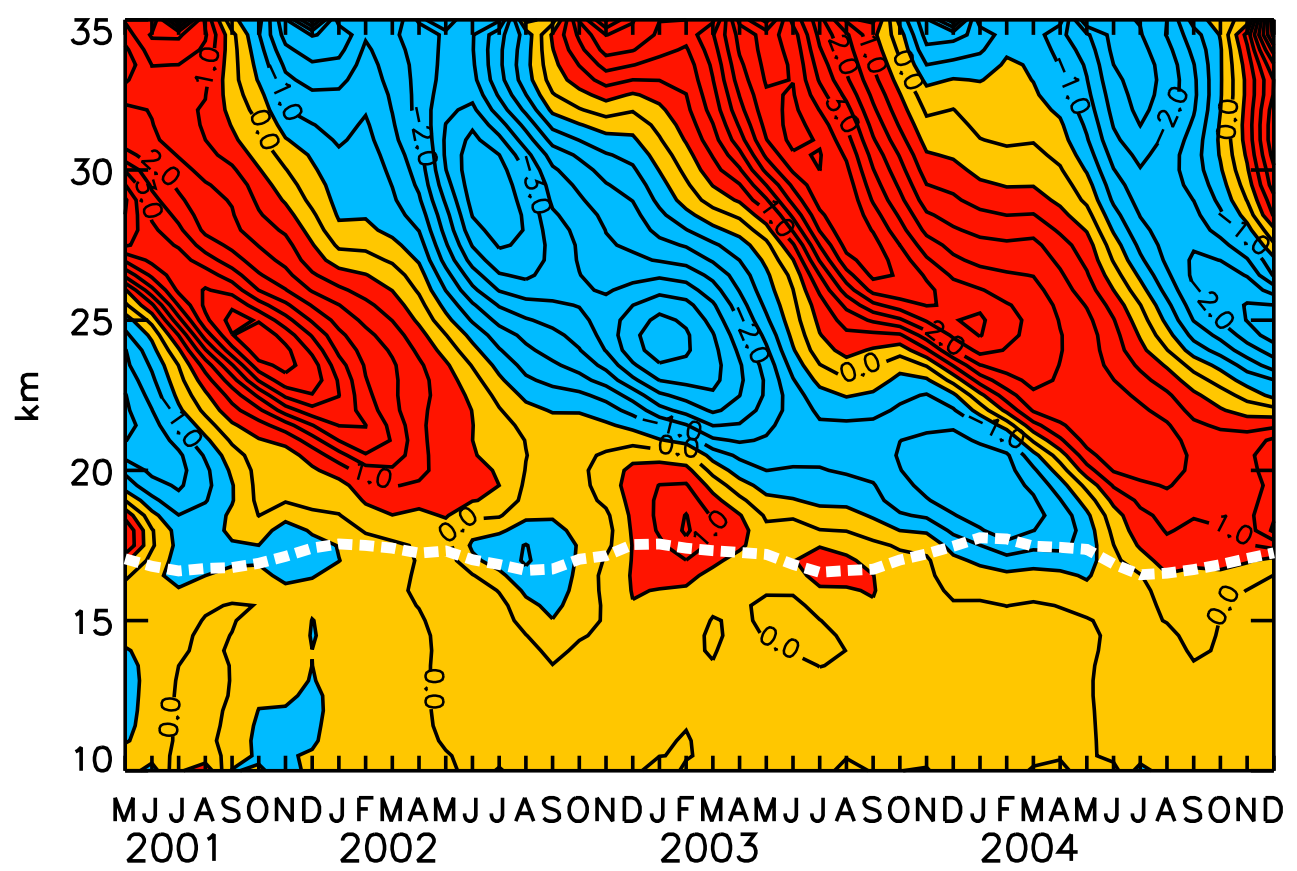

Fig. 12. Temperature anomalies (blue: negative, red: positive) over the equator region $\left(4^{\circ} \mathrm{S}-4^{\circ} \mathrm{N}\right)$ from $\mathrm{CHAMP}$ measurements for the period May 2001-December 2004. Contours are $\pm 0.5 \mathrm{~K}$. The heavy white dashed line shows the monthly-mean CPT altitude (update from Schmidt et al. (2004b)).

because the jet stream axis is on the southern side of the maximum altitude (pressure) gradients (see Figs. 7a, b) whereas the strongest temperature gradients lie above the jet stream axis (Hoinka, 1999). These are also the areas with largest differences between GPS RO and ECMWF.

The reasons for the larger deviations in the jet stream areas are open points and topics of further studies. One reason could be the already mentioned different vertical resolution of both data sets. In the jet stream areas tropopause breaks and folds often occur (Elbern et al., 1998; Sørensen and Nielsen, 2001; Sprenger et al., 2003; Pan et al., 2004) leading to multiple tropopauses as seen, e.g., in the CHAMP temperature profile from Fig. 4, whereas the ECMWF model can not always resolve such small temperature changes. Because we only consider the first tropopause that fulfills the WMO criteria the differences from Figs. 10 and 11 in the jet stream region can be explained.

The small temperature changes, which are not resolved by the ECMWF model, could be connected with gravity wave activities. This interpretation is supported by, e.g., global gravity wave momentum flux calculations from the CRISTA (Cryogenic Infrared Spectrometers and Telescopes for the Atmosphere) instrument (Ern et al., 2004). These authors have found high momentum fluxes (at $25 \mathrm{~km}$ ) for August 1997 in the edge of the Antarctic polar vortex, above the Gulf of Mexico, and east of China and Japan. These are also regions of large differences between CHAMP/SAC-C and ECMWF LRT parameters for the NH summer months (Figs. 10b, d, f).
An other point that should be considered here is the hydrostatic approximation and the spherical symmetry assumed in the $\mathrm{RO}$ retrieval software, that could be invalid in the jet stream areas, especially when associated with strong convection as above the Asian land mass and warm western Pacific during the NH summer months. This will be a topic of further research.

\section{The equatorial QBO}

Randel et al. (2003) have first shown the quasi-biennial oscillation (QBO) pattern in GPS RO temperature data for the GPS/MET data. Schmidt et al. (2004b) followed with the first 31 months from CHAMP data. We present here an update of the latter study using the complete time period from May 2001-December 2004 (Fig. 12). The plot results from the following algorithm: monthly means of temperature and the annual cycle based on 3- or 4-year values (2001-2004), respectively, were calculated but separately for each altitude level between $10-35 \mathrm{~km}$ in $0.5 \mathrm{~km}$ intervals over the equator $\left(4^{\circ} \mathrm{S}-4^{\circ} \mathrm{N}\right)$. Subtracting the annual temperature cycle from the individual monthly means leads to Fig. 12 showing the monthly temperature anomalies in the UTLS over the equator region. The downward propagating patterns in the lower stratosphere have a period of about two years with maximum deviations of $\pm 4.5 \mathrm{~K}$ between 22 and $31 \mathrm{~km}$. At the tropopause level the anomalies are decreased to about $\pm 0.5 \mathrm{~K}$. These temperature anomaly patterns are caused by 
the stratospheric QBO (Randel et al., 1999; Baldwin et al., 2001; Huesmann et al., 2001; Ribera et al., 2003). Figure 12 is also in agreement with QBO patterns found in the data from the GPS/MET experiment (Randel et al., 2003).

\section{Conclusions}

The GPS RO is a relatively new remote sounding technique of the atmosphere. At GFZ Potsdam the first long-term RO data set is created from the CHAMP satellite mission. The temperature bias between CHAMP and independent radiosonde measurements is less than $1.5 \mathrm{~K}$ between 300 $10 \mathrm{hPa}(2-3 \mathrm{~K}$ standard deviation). Between 200 and $20 \mathrm{hPa}$ the bias is less than $0.5 \mathrm{~K}$ (standard deviation of about $2 \mathrm{~K}$ ). On this basis global LRT tropopause pressure, temperature, potential temperature, and sharpness derived from CHAMP and SAC-C RO temperatures profiles for the period May 2001-December 2004 have been discussed.

The main results on LRT pressure, temperature, and potential temperature are consistent with those of other investigations found in the literature (Hoinka, 1998; Highwood and Hoskins, 1998; Hoinka, 1999; Randel et al., 2000; Highwood et al., 2000; Seidel et al., 2001; Zängl and Hoinka, 2001; Gettelman and de Forster, 2002). New results from tropopause sharpness were introduced. Normalised LRT sharpness is highest in the Arctic region during NH summer (about 1.8) and Antarctica in SH summer but with lower values (1.5). During the winter months the sharpness decreases to values less than 1 in the polar regions. In the tropics the variation of the sharpness is less during the year compared with the polar regions. A maximum sharpness all year long is observed over the western Pacific "warm pool" region with slightly higher values during $\mathrm{NH}$ winter (1.6-1.8). High sharpness values $(1.2-1.4)$ are found during $\mathrm{NH}$ winter between $40^{\circ} \mathrm{N}-60^{\circ} \mathrm{N}$ over the Atlantic and eastern Pacific. On total average the normalised sharpness is above 1, except for the STJ region. Highest values $(>1.5)$ are found over areas with large convection in the tropics.

Comparisons between CHAMP/SAC-C tropopause parameters and ECMWF show on average the largest differences in the vicinity of the jet streams with up to $700 \mathrm{~m}$ in LRT altitude and $3 \mathrm{~K}$ in LRT temperature, respectively.

Because of accuracy, high vertical resolution, and globally distributed temperature data in the tropopause region the RO technique is suitable for global monitoring of the UTLS as an important part of the atmosphere. Changes in tropopause parameters can be used for the detection of climate change as already shown by Sausen and Santer (2003).

The CHAMP RO experiment will be followed by other missions (GRACE, COSMIC, MetOp, TerraSAR-X, EQUARS) establishing the RO technique for global temperature monitoring in the UTLS region.
Acknowledgements. We thank K. Schöllhammer and the Institute for Meteorology at the Free University Berlin for delivering radiosonde data and the ECMWF for supplying global weather analyses. We thank the anonymous referees for their helpful comments. We thank COST 723 for paying the publication charge of the paper.

Edited by: A. Richter

\section{References}

Anthes, R. A., Rocken, C., and Kuo, Y. H.: Applications of COSMIC to meteorology and climate, Terrestrial, Atmospheric and Ocean Sciences, 11, 115-156, 2000.

Baldwin, M. P., Gray, L. J., Dunkerton, T. J., Hamilton, K., Haynes, P. H., Randel, W. J., Holton, J. R., Alexander, M. J., Hirota, I., Horinouchi, T., Jones, D. B. A., Kinnersley, J. S., Marquardt, C., Sato, K., and Takahashi, M.: The quasi-biennial oscillation, Rev. Geophysics, 39, 179-229, 2001.

Birner, T., Dörnbrack, A., and Schumann, U.: How sharp is the tropopause at midlatitudes?, Geophys. Res. Lett., 29, doi:10.1029/2002GL015142, 2002.

Birner, T.: The extratropical tropopause region, $\mathrm{PhD}$ thesis (in German), DLR Oberpfaffenhofen, Germany, 2003.

Elbern, H., Hendricks, J., and Ebel, A.: A climatology of tropopause folds by global analyses, Theor. Appl. Climatol., 59, 181-200, 1998.

Ern, M., Preusse, P., Alexander, M. J., and Warner, C. D.: Absolute values of gravity wave momentum flux derived from satellite data, J. Geophys. Res., 109, D20103, doi:10.1029/2004JD004752, 2004.

Fjeldbo, G., Kliore, A. J., and Eshleman, V. R.: The neutral atmosphere of Venus as studied with the Mariner V radio occultation experiments, Astron. J., 76, 123-140, 1971.

Gettelman, A. and de Forster, P. M.: A climatology of the tropical tropopause layer, J. Meteorol. Soc. Japan, 80, 911-924, 2002.

Hajj, G. A., Ao, C. O., Iijima, B. A., Kuang, D., Kursinski, E. R., Mannucci, A. J., Meehan, T. K., Romans, L. J., de la Torre Juarez, M., and Yunck, T. P.: CHAMP and SAC-C atmospheric occultation results and intercomparisons, J. Geophys. Res., 109, doi:10.1029/2003JD003909, 2004.

Highwood, E. J. and Hoskins, B. J.: The tropical tropopause, Q.J.R. Meteorol. Soc., 124, 1579-1604, 1998.

Highwood, E. J., Hoskins, B. J., and Berrisford, P.: Properties of the Arctic tropopause, Q. J. R. Meteorol. Soc., 126, 1515-1532, 2000.

Hoinka, K. P.: Statistics of the global tropopause pressure, Mon. Weather Rev., 126, 3303-3325, 1998.

Hoinka, K. P.: Temperature, humidity, and wind at the global tropopause, Mon. Weather Rev., 127, 2248-2265, 1999.

Holton, J. R., Haynes, P. H., McIntyre, M. E., Douglass, A. R., Rood, R. B., and Pfister, L.: Stratosphere-troposphere exchange, Rev. Geophysics, 33, 403-439, 1995.

Huesmann, A. S. and Hitchman, M. H.: The stratospheric quasibiennial oscillation in the NCEP reanalyses: Climatological structures, J. Geophys. Res., 106(D11), 11859-11874, 2001.

Jensen, A. S., Lohmann, M., Benzon, H. H., and Nielsen, A.: Full Spectrum inversion of radio occultation signals, Radio Sci., 38(3), doi:10.1029/2002RS002763, 2003. 
König, R., Michalak, G., Neumayer, K. H., Schmidt, R., Zhu, S. Y., Meixner, H., and Reigber, C.: Recent developments in CHAMP orbit determination at GFZ, in: Earth Observation with CHAMP, edited by: Reigber C., Lühr, H., Schwintzer, P., and Wickert, J., Springer, Berlin (ISBN 3-540-22804-7), 65-70, 2005.

Kuo, Y. H., Wee, T. K., Sokolovskiy, S., Rocken, C., Schreiner, W. S., Hunt, D., and Anthes, R. A.: Inversion and error estimation of GPS radio occultation, J. Meteorol. Soc. Japan, 82(1B), 507531, 2004.

Kuo, Y. H., Schreiner, W. S., Wang, J., Rossiter, D. L., and Zhang, Y.: Comparison of GPS radio occultation soundings with radiosondes, Geophys. Res. Let., 32, L05817, doi:1029/2004GL021443, 2005.

Kursinski, E. R., Hajj, G. A., Hardy, K. R., Schofield, J. T., and Linfield, R.: Observing Earth's atmosphere with radio occultation measurements using the Global Positioning System, J. Geophys. Res., 102, 23 429-23 465, 1997.

Melbourne, W. G., Davis, E. S., Hajj, G. A., Hardy, K. R., Kursinski, E. R., Meehan, T. K., and Young, L. E.: The application of spaceborne GPS to atmospheric limb sounding and global change monitoring, JPL Publication, Jet Propulsion Laboratory, Pasadena, California, 94-18, 1994.

Nishida, M., Shimizu, A., Tsuda, T., Rocken, C., and Ware, R. H.: Seasonal and longitudinal variations in the tropical tropopause observed with the GPS occultation technique (GPS/MET), J. Meteorol. Soc. Japan, 78, 691-700, 2000.

NOAA/NASA/USAF: US Standard Atmosphere 1976, Technical report, U.S. Government Printing Office, Washington, DC, 1976.

Pan, L. L., Randel W. J., Gary, B. L., Mahoney, M. J., and Hintsa, E. J.: Definitions and sharpness of teh extratropical tropopause: A trace gas perspective, J. Geophys. Res., 109, D23103, doi:10.1029/2004JD004982, 2004.

Randel, W. J., Wu, F., Swinbank, R., Nash, J., and O’Neill, A.: Global QBO circulation derived from UKMO stratospheric analyses, J. Atmos. Sci., 56, 457-474, 1999.

Randel, W. J., Wu, F., and Gaffen, D. J.: Interannual variability of the tropical tropopause derived from radiosonde data and NCEP reanalyses, J. Geophys. Res., 105(D12), 15 509-15 523, 2000.

Randel, W. J., Wu, F., and Rios, W. R.: Thermal variability of the tropical tropopause region derived from GPS/MET observations, J. Geophys. Res., 108(D1), 4020, doi:10.1029/2002JD002595, 2003.

Ribera, P., Gallego, D., Pena-Ortiz, C., Gimeno, L., Garcia-Herrera, R., Hernandez, E., and Calvo, N.: The stratospheric QBO signal in the NCEP reanalysis, 1958-2001, Geophys. Res. Lett., 30(13), 1691, doi:10.1029/2003GL017131, 2003.

Rocken, C., Anthes, R. A., Exner, M., Hunt, D., Sokolovskiy, S., Ware, R., Gorbunov, M., Schreiner, W., Feng, D., Herman, B., Kuo, Y. H., and Zou, X.: Analysis and validation of GPS/MET data in the neutral atmosphere, J. Geophys. Res., 102(D25), 29 849-29 866, 1997.

Sausen, R. and Santer, B. D.: Use of changes in tropopause height to detect influences on climate, Meteorol Z, 12(3), 131-136, 2003.

Santer, B. D., Wigley, T. M. L., Simmons, A. J., Kallberg, P. W., Kelly, G. A., Uppala, S. M., Ammann, C., Boyle, J. S., Brüggemann, W., Doutriaux, C., Fiorino, M., Mears, C., Meehl, G. A., Sausen, R., Taylor, K. E., Washington, W. M., Wehner, M. F., and Wentz, F. J.: Identification of anthropogenic climate change using a second-generation reanalysis, J. Geophys. Res.,
109, D21104, doi:10.1029/2004DJ005075, 2004.

Schmidt, T., Wickert, J., Marquardt, C., Beyerle, G., Reigber, C., Galas, R., and König, R.: GPS radio occultation with CHAMP: An innovative remote sensing method of the atmosphere, Adv. Space Res., 33, 1036-1040, 2004a.

Schmidt, T., Wickert, J., Beyerle, G., and Reigber, C.: Tropical tropopause parameters derived from GPS radio occultation measurements with CHAMP, J. Geophys. Res., 109, D13105, doi:10.1029/2004JD004566, 2004b.

Schmidt, T., Wickert, J., Beyerle, G., König, R., Galas, R., and Reigber, C.: The CHAMP atmospheric processing system for radio occultation measurements, in: Earth Observation with CHAMP, edited by: Reigber C., Lühr, H., Schwintzer, P., and Wickert J., Springer, Berlin (ISBN 3-540-22804-7), 597-602, 2005.

Schoeberl, M. R.: Extratropical stratosphere-troposphere mass exchange, J. Geophys. Res., 109, D13303, doi:10.1029/2004JD004525, 2004.

Seidel, D. J., Ross, R. J., Angell, J. K., and Reid, G. C.: Climatological characteristics of the tropical tropopause as revealed by radiosondes, J. Geophys. Res., 106(D8), 7857-7878, 2001.

Smith, E. and Weintraub, S.: The constants in the equation for atmospheric refractive index at 20 radio frequencies, Proceedings of the I.R.E., 41, 1035-1037, 1953.

Sørensen, J. H. and Nielsen, N. W.: Intrusion of stratospheric ozone to the free troposphere through tropopause folds - a case study, Phys. Chem. Earth (B), 26, 801-806, 2001.

Sprenger, M., Maspoli, M. C., and Wernli, H.: Tropopause folds and cross-tropopause exchange: A global investigation based upon ECMWF analyses for the time period March 2000 to February 2001, J. Geophys. Res., 108(D12), 8518, doi:10.1029/2002JD002587, 2003.

Vorobev, V. V. and Krasilnikova, T. G.: Estimation of the accuracy of the atmospheric refractive index recovery from Doppler shift measurements at frequencies used in the NAVSTAR system, Phys. of the Atmosph. and Ocean, 29, 602-609, 1994.

Wang, D. Y., Stiller, G. P., von Clarmann, T., Fischer, H., LópezPuertas, M., Funke, B., Glatthor, N., Grabowski, U., Höpfner, M., Kellmann, S., Kiefer, M., Linden, A., Tsidu, G. W., Milz, M., Steck, T., Jiang, J. H., Ao, C. O., Manney, G., Hocke, K., Wu, D. L., Romans, L. J., Wickert, J., and Schmidt, T.: Crossvalidation of MIPAS/ENVISAT and GPS-RO/CHAMP temperature profiles, J. Geophys. Res., 109, doi:10.1029/2004JD004963, 2004.

Ware, R., Exner, M., Feng, D., Gorbunov, M., Hardy, K., Melbourne, W., Rocken, C., Schreiner, W., Sokolovsky, S., Solheim, F., Zou, X., Anthes, R., Businger, S., and Trenberth K.: GPS soundings of the atmosphere from low earth orbit: Preliminary results, Bull. Amer. Meteor. Soc., 77, 19-40, 1996.

Wickert, J., Galas, R., Beyerle, G., König, R., and Reigber, C.: GPS ground station data for CHAMP radio occultation measurements, Phys. Chem. Earth (A), 26, 503-511, 2001a.

Wickert, J., Reigber, C., Beyerle, G., König, R., Marquardt, C., Schmidt, T., Grunwaldt, L., Galas, R., Meehan, T. K., Melbourne, W. G., and Hocke, K.: Atmosphere sounding by GPS radio occultation: First results from CHAMP, Geophys. Res. Lett., 28, 3263-3266, 2001b.

Wickert, J., Schmidt, T., Beyerle, G., König, R., Reigber, C., and Jakowski, N.: The radio occultation experiment aboard CHAMP: 
Operational data analysis and validation of atmospheric profiles, J. Meteorol. Soc. Japan, 82(1B), 381-395, 2004a.

Wickert, J.: Comparison of vertical refractivity and temperature profiles from CHAMP with radiosonde measurements, Scientifical Technical Report GFZ Potsdam, STR 04/19, ISSN 16100956, http://www.gfz-potsdam.de/bib/zbstr.htm, 2004 b.

Wickert, J., Beyerle, G., König, R., Heise, S., Grunwaldt, L., Michalak, G., Reigber, C., and Schmidt, T.: GPS radio occultation with CHAMP and GRACE: A first look at a new and promising satellite configuration for global atmospheric sounding, Ann. Geophys., 23, 653-658, 2005,

SRef-ID: 1432-0576/ag/2005-23-653.
Wirth, V.: Thermal versus dynamical tropopause in uppertropospheric balanced flow anomalies, Q. J. R. Meteorol. Soc., 126, 299-317, 2000.

World Meteorological Organisation (WMO): Definition of the tropopause, WMO Bull., 6, Geneva, 1957.

Zängl, G. and Hoinka, K. P.: The tropopause in the Polar regions, J. Climate, 14, 3117-3139, 2001. 